\title{
CARACTERIZAÇÃO DE SEMENTES DE ACESSOS DE Passiflora cincinnata MAST DO ESTADO DA BAHIA
}

\author{
Larissa de Souza Pereira $^{1}$; Claudinéia Regina Pelacani ${ }^{2}$; Lourival Palmeira Gonçalves \\ Neto $^{3}$; David Santana Guimarães ${ }^{3}$ \\ 1. Bolsista PROBIC/UEFS, Graduanda em Agronomia, Universidade Estadual de Feira de Santana, e-mail: \\ lary_xique@hotmail.com \\ 2. Orientadora, Departamento de Biologia, Universidade Estadual de Feira de Santana, e-mail: \\ claudineiapelacani@gmail.com \\ 3. Mestrando em Recursos Genéticos Vegetais, Departamento de Biologia, Universidade Estadual de Feira de Santana, e- \\ mail: lourivalpgneto@yahoo.com.br; davidsg2005@hotmail.com
}

PALAVRAS-CHAVE: maracujá-do-mato; melhoramento genético, Passiflora cincinnata.

\section{INTRODUÇÃO}

Passiflora cincinnata Mast conhecido popularmente como maracujá-do-mato é uma espécie silvestre de grande potencial econômico, pois apresenta características agronômicas favoráveis que podem ser utilizadas em programas de melhoramento genético do maracujá comercial Passiflora edulis (MELLETI, 2005).

O maracujazeiro é propagado preferencialmente por sementes a partir de frutos maduros, sendo a característica da semente uma característica importante para a escolha do material propagativo (LIMA, 2002). O estudo dessas características é de suma importância, pois garantem a escolha de sementes uniformes, seja de tamanho e fidelidade genética. Mateus e Lopes (2007) afirmam que essas características são importantes para seleção de genótipo promissor, principalmente quando o material a ser estudado são espécies ainda pouco conhecidas ou de origem espontânea, como a espécie $P$. cincinnata, cujas sementes apresentam desuniformidade na taxa de emergência por possuir restrição endógena e baixa longevidade.

O objetivo do trabalho foi caracterizar sementes quanto às medidas biométricas dos acessos de maracujá-do-mato encontrados em diferentes localidades da Bahia.

\section{METODOLOGIA}

Para realização deste trabalho foram utilizadas sementes de acessos de Passiflora cincinnata. As sementes foram provenientes de frutos maduros obtidos em diferentes localidades do

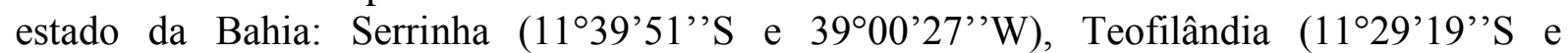
$\left.38^{\circ} 59^{\prime} 52^{\prime \prime} \mathrm{W}\right)$, Ipirá $\left(12^{\circ} 09^{\prime} 30^{\prime}\right.$ 'S e $39^{\circ} 44^{\prime} 14^{\prime}$ 'W), Itaetê $\left(12^{\circ} 59^{\prime} 11^{\prime}\right.$ 'S 3 e $\left.40^{\circ} 58^{\prime} 21^{\prime \prime} \mathrm{W}\right)$ e Souto Soares $\left(12^{\circ} 5^{\prime} 21^{\prime}\right.$ 'S e $\left.41^{\circ} 38^{\prime} 17^{\prime \prime} \mathrm{W}\right)$ perfazendo um total de cinco acessos. As sementes foram retiradas dos frutos e transferidas para peneira de alumínio com intuito de retirar o arilo através da fricção feita pelas mãos. Após este processo, as sementes lavadas foram dispostas sobre toalha de papel em condições de laboratório para que ocorra secagem durante um periodo de 48 horas, revolvendo-as a cada intervalo de 12 horas.

Foram tomadas medidas a partir do 'pool' de sementes de cada acesso. Uma subamostra retirada de cada acesso, composta de 50 sementes e dividida em cinco repetições, foram analisadas quanto às medidas de comprimento (distância do ápice à base), largura e espessura (região mediana) utilizando paquímetro digital (mm).

Uma segunda subamostra, composta de 200 sementes e dividida em quatro repetições, foi utilizada para obtenção da massa fresca $(\mathrm{g})$. O conteúdo de umidade das sementes foi avaliado 
mediante a secagem pelo método padrão (RAS), em estufa de circulação forçada de $\operatorname{ar}, 105^{\circ} \mathrm{C}$ por 24 horas. $\mathrm{O}$ conteúdo de umidade foi analisado pela expressão: $\mathrm{CU}=($ Peso inicial - Peso final) / (Peso inicial) x 100\%

Ao final das medições foram separados lotes de 100 e 1000 sementes para cada acesso para análise de sua massa (g) com auxílio de balança analítica. Utilizando uma mini-cartela de cores RHS (Royal Horticultural Society), foi comparada a variação da coloração da testa das sementes para os cinco acessos de maracujá do mato.

Para fins de conservação do vigor o 'pool' de sementes secas de cada acesso de maracujá foi mantido em sacos de papel tipo pipoca, identificados e introduzidos em potes de vidro herméticos com sílica ao fundo e mantidos em ambiente refrigerado $\left(8^{\circ} \mathrm{C}\right)$ até o momento dos demais ensaios.

O delineamento experimental foi inteiramente casualizado. Os dados foram submetidos à analise de variância e as médias comparadas pelo teste de Tukey ao nível de probabilidade de $5 \%$.

\section{RESULTADOS E DISCUSSÃO}

Sementes dos acessos de maracujá do mato apresentaram conteúdo de água inicial variando entre 7,10 e $8,17 \%$ (Tabela 1). Os valores encontrados pelo método de secagem em estufa com circulação do ar foi menor do que observado por Oliveira Junior (2008) onde obteve um valor médio de 10,22\% trabalhando com sementes da mesma espécie. Os valores de conteúdo de água estão dentro dos limites considerados para sementes classificadas como tolerantes à dessecação (CARVALHO; NAKAGAWA, 2012), por sua vez algumas espécies de Passiflora mostram sensíveis a baixos conteúdos de água ao longo do armazenamento. Segundo os autores (CARVALHO; NAKAGAWA, 2012), a maioria dos genótipos cujas sementes toleram a redução do conteúdo de água no processo final de desenvolvimento, representa um mecanismo eficiente de manter importantes características fisiológicas das sementes como a vigor, a viabilidade e capacidade germinativa.

O tegumento externo dos frutos maduros de maracujá do mato apresentou coloração predominante escura (Dark Brown) (Figura 1), entretanto foi observada variabilidade entre os acessos quanto aos aspectos biométricos das sementes. Segundo Haliski et al. (2013), o estudo da morfologia de sementes pode fazer entender o processo germinativo, além de favorecer a conservação e utilização da espécie. Os dados de biometria de sementes que envolvem genótipos com características importantes como os maracujazeiros, são uteis para conservação dos recursos genéticos, além de avaliar a variabilidade genética entre eles (VIEIRA; GUSMÃO, 2008). A tabela 1 e figura 1 mostram as principais características físicas verificadas entre os cinco acessos estudados. Sementes do acesso Teofilândia e Ipirá apresentaram menor comprimento e largura média, respectivamente.

Tabela 1. Valores médios das características de sementes de Passiflora cincinnata MAST 


\begin{tabular}{lcccccc}
\hline Acesso & $\begin{array}{c}\text { CS } \\
(\mathrm{mm})\end{array}$ & $\begin{array}{c}\text { LS } \\
(\mathbf{m m})\end{array}$ & $\begin{array}{c}\text { ES } \\
(\mathrm{mm})\end{array}$ & $\begin{array}{c}\text { CU } \\
(\%)\end{array}$ & $\begin{array}{c}\text { P100S } \\
(\mathrm{g})\end{array}$ & $\begin{array}{c}\text { P1000S } \\
(\mathrm{ml})\end{array}$ \\
\hline Serrinha & $5.93 \mathrm{a}$ & $3.69 \mathrm{ab}$ & $2.41 \mathrm{a}$ & $7.98 \mathrm{a}$ & $2.55 \mathrm{bc}$ & $26.48 \mathrm{a}$ \\
Itaetê & $6.03 \mathrm{a}$ & $3.77 \mathrm{a}$ & $2.50 \mathrm{a}$ & $8.17 \mathrm{a}$ & $2.86 \mathrm{a}$ & $28.74 \mathrm{a}$ \\
Ipirá & $5.73 \mathrm{ab}$ & $3.58 \mathrm{~b}$ & $2.38 \mathrm{a}$ & $7.27 \mathrm{~b}$ & $2.45 \mathrm{~d}$ & $23.31 \mathrm{c}$ \\
Teofilândia & $5.55 \mathrm{~b}$ & $3.70 \mathrm{ab}$ & $2.42 \mathrm{a}$ & $7.10 \mathrm{~b}$ & $2.48 \mathrm{~cd}$ & $24.49 \mathrm{bc}$ \\
S Soares & $5.95 \mathrm{a}$ & $3.67 \mathrm{ab}$ & $2.38 \mathrm{a}$ & $8.01 \mathrm{a}$ & $2.66 \mathrm{~b}$ & $26.50 \mathrm{ab}$ \\
\hline & & & & & 2.21 & 3.98 \\
\hline
\end{tabular}

Médias seguidas por mesma letra nas colunas não diferem entre si, pelo teste de Tukey a 5\%. CS= Comprimento da semente; LS= Largura da semente; ES= Espessura da semente; CU= Conteúdo de água; Peso de 100 sementes; Peso de 1000 sementes.

Figura 1. Coloração e formato das sementes dos acessos de maracujá do mato. (A) Serrinha, (B) Itaetê, (C) Ipirá, (D) Teofilândia, (E) Souto Soares (Coloração Dark Brown)

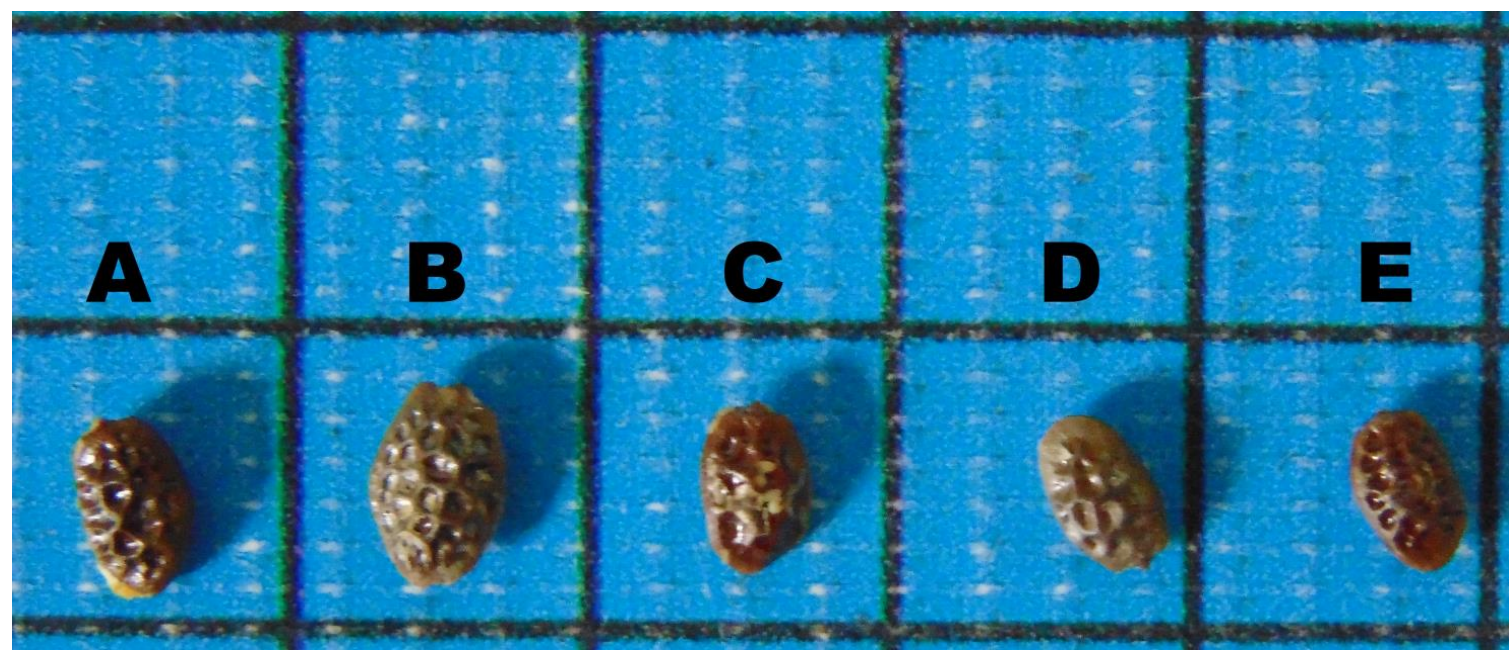

Na figura 1 observou-se que as sementes do maracujazeiro apresentaram variação quanto ao tamanho, onde também influenciou no peso (Tabela 1) e por via indireta podem refletir na diversidade do processo de germinação e obtenção de mudas de maracujá. As sementes apresentaram comprimento variando entre 5,55 a $6,03 \mathrm{~mm}$, a largura variando entre 3,58 a 3,77 mm, e a espessura não apresentou diferença significativa. Em geral, as sementes dos maracujazeiros são comprimidas lateralmente, com testa reticulada ou mais ou menos verrucosa (BARROSO et al., 2004), podendo ser verificado esses mesmos aspectos morfológicos no estudo realizado com as sementes do maracujá do mato.

\section{CONCLUSÃO}

A variabilidade genética encontrada para sementes de $P$. cincinnata é muito importante visando à seleção de genótipos promissores dentro do melhoramento genético das espécies. Os acessos Itaetê e Souto Soares apresentaram as melhores médias para a maior parte das variáveis analisadas nas sementes, sendo os genótipos de boa qualidade e com potencial para serem utilizados em programas de melhoramento genético. 


\section{REFERÊNCIAS}

BARROSO, G.M.; MORIM, M.P.; PEIXOTO, A.L.; ICHASO, C.L.F. Frutos e Sementes: morfologia aplicada à sistemática e dicotiledôneas. Editora UFV, Viçosa, MG, 443p. 2004.

CARVALHO, N.M.; NAKAGAWA, J. Sementes: ciência, tecnologia e produção. Jaboticabal: FUNESP, 2012.

HALISKI, S; COSMO, N.L; GOGOZ, A.M; REGO, S.S; NOGUEIRA, A.C; KUNIYOSHI, Y.S. Caracterização morfológica de frutos, sementes, plântulas e germinação de sementes de Casearia decandra. Pesquisa Florestal Brasileira, v.33, n.75, p. 253-259, jul/set, 2013.

LIMA, A.A.; TRINDADE, A.V. Propagação. In: LIMA, A.A. (Ed). Maracujá Produção: Aspectos técnicos. Brasília, DF: Embrapa Informação Tecnológica, p. 10, 2002.

MATHEUS, M.T.; LOPES, J.C. Morfologia de frutos, sementes e plântulas e germinação de sementes de Erythrina variegata L. Revista Brasileira de Sementes, vol.29, n.3, p.8-15. 2007.

MELLETI, L.M.M.; SCOTT, M.D.S.; BERNACCI, L.C.; PASSOS, I.R.S. Melhoramento genético do maracujá: passado e futuro. In: FALEIRO, G.F.; JUNQUEIRA, N.T. V; BRAGA, M.F. Maracujá: germoplasma e melhoramento genético. Planaltina, DF: Embrapa Cerrados, 2005.

OLIVEIRA JUNIOR, M.X de. Caracterização dos frutos do maracujazeiro-do-mato (Passiflora cincinnata mast.) e superação de dormência de sementes, 2008. 61f. Dissertação (Mestrado em Agronomia) Universidade Estadual do Sudoeste da Bahia.

VIEIRA, F.A.; GUSMÃO, E. Biometria, armazenamento de sementes e emergência de plântulas de Talisia esculenta Radlk. (Sapindaceae). Ciência \& Agrotecnologia, v.32, n.4, p.1073-1079, jul./ago., 2008. 